\title{
The Mechanical Transmission and some Properties of Potato Paracrinkle Virus
}

\author{
BY F. C. BAWDEN, B. KASSANIS AND H. L. NIXON \\ Rothamsted Experimental Station, Harpenden, Hertfordshire
}

SUMMARY: With the aid of abrasives, paracrinkle virus, hitherto transmitted only by grafting, was transmitted to Arran Victory potatoes by inoculation with sap from infected plants, either symptomless King Edward or diseased Arran Victory. The proportion of plants that became infected was increased when they were kept in darkness for some days before inoculation.

Tomato plants were more readily infected than Arran Victory potatoes, no abrasive being needed. Infected tomatoes were symptomless, but electron microscopy showed their sap to contain rod-shaped particles of variable lengths and about $10 \mathrm{~m} \mu$. wide. Such particles have not been found in uninfected tomatoes and they are presumed to be the virus; they were destroyed by heating at $60^{\circ}$.

The nature of similar particles in King Edward and Arran Victory potatoes with paracrinkle is uncertain, because rod-shaped particles were also found in uninfected Arran Victory. Rod-shaped particles also occurred in uninfected plants of all other potato varieties examined and in newly raised potato seedlings; they were not transmitted, either by inoculation or by grafting, to tomato or other hosts tested, and they withstood heating to $98^{\circ}$.

These results with paracrinkle parallel those with certain other plant viruses. They invalidate theories that postulate its origin as a consequence of grafting and render unnecessary the concept that it is intrinsic to King Edward potatoes.

Salaman \& Le Pelley (1930) gave the name paracrinkle to a disease which they found was produced when plants of certain potato varieties, particularly Arran Victory, were grafted with scions from apparently normal plants of the variety King Edward. They failed to cause paracrinkle by inoculating Arran Victory plants with sap from King Edward plants and attributed the disease to a grafttransmissible virus for which King Edward plants are symptomless carriers. Their original observations have been repeatedly confirmed and the many King Edward plants that have since been examined by grafting to Arran Victory have all been found to cause paracrinkle (Salaman, 1932; Barton-Wright \& McBain, 1933). Indeed, although it is obviously impossible to prove, it seems highly probable that paracrinkle virus occurs in every plant of this clonal variety. Despite the fact that King Edward has been extensively grown for many years, and so has provided abundant sources of the virus, paracrinkle virus has not been recorded as occurring in any other potato variety in the field. It seemed reasonable to infer from this that the virus has no natural method of spread, which in turn implied that the virus was present in the original seedling from which the clone has developed, and that it has survived and multiplied only because its host is propagated vegetatively.

When first drawing attention to the inferences possible from the known occurrence of paracrinkle virus, Bawden $(1939$, p. 258) pointed out that, if the original King Edward seedling became infected from some external source, it seemed necessary to assume that the virus had some natural method of 
spread which it has since lost. He suggested that it was equally plausible to assume that the virus had arisen de novo in the variety, but, as nothing definite is known about the origin or early treatment of the clone, stressed the speculative nature of any interpretations. Since then paracrinkle has figured prominently in discussions on the origins of viruses (Darlington, 1944, 1949; van der Plank, 1948), with statements becoming increasingly positive, although there has been little further work on the virus. That it is intrinsic to King Edward seems to have been accepted as established, and Darlington (1944), completely ignoring the fact that nothing is known about the chemical nature of paracrinkle virus, stated that 'What is a stable and presumably useful cell protein with one genotype acts as a destructive agent with another'. He also stated that 'the virus must have arisen by grafting' and claimed that it provided evidence that there is no essential difference between viruses and plasmagenes (the hypothetical units that determine cytoplasmic inheritance). King Edward rarely flowers and sets seed, so that the inheritance of paracrinkle virus is difficult to study on a large scale. However, Carson, Howard, Markham \& Smith (1944) obtained twenty-two seedlings from the cross King Edward (female) by Flourball and found them all to be free from paracrinkle virus. These results are inadequate evidence that transmission through the egg never occurs, but at least show that such transmission can be regarded as exceptional rather than normal. Despite this difference between the behaviour of paracrinkle virus and a plasmagene, Darlington (1949) has continued to relate the two; to stress its origin from a normal plant constituent, he has separated it from other plant viruses, placing it in a group which he has called provirus, of which the distinguishing character is transmissible only by grafting.

Paracrinkle provides an excellent example of the manner in which theories can grow when they are untrammelled by facts, for the wealth of speculation about it is matched only by the poverty of knowledge. The work described in this paper was started to gain some information about the properties and transmission of this academically interesting virus, which also has the potentialities of a dangerous pathogen; it is still far from complete, but the results so far obtained suggest that at least some of the premises on which theories have been based are erroneous.

\section{MATERIALS AND METHODS}

The source of paracrinkle virus was provided by Stock Seed King Edward plants, which, from their appearance and the negative results of transmission tests to tobacco (Nicotiana tabacum, var. White Burley), N. glutinosa, Datura stramonium and tomato (Lycopersicum esculentum), var. Kondine Red, seemed to be free from all other known potato viruses. The presence of paracrinkle virus was readily demonstrated by grafting scions to Arran Victory potato plants, all of which developed symptoms. As noted by Salaman \& Le Pelley (1930), the severity of symptoms varied widely in different plants, even when these were grafted with scions from the same King Edward plant. The new shoots of some plants developed symptoms within 10-12 days of grafting, the young leaves 
showing a blotchy yellow mottle, becoming crinkled and deformed, and growing much more slowly than normal. In other plants, symptoms developed less rapidly and were less severe; growth was little checked, and the leaves showed various degrees of mottling and waving. Symptoms were more uniform in the progeny from these plants raised from tubers in the next year, but there was still some variation. Most were much dwarfed, with small and highly crinkled leaves. Some, however, were less severely affected and at first grew almost normally but later became mottled and crinkled. Similar variations sometimes occurred between individual shoots from one tuber, some being acutely affected and others almost normal.

Salaman (1932) noted such variations and interpreted them as showing that paracrinkle is caused by a complex of two viruses that occasionally disrupts, so that a shoot or plant contains only one. We have found no evidence to support this, for tubers from mildly affected plants have given rise to severely affected plants as often as not. This also suggests that the phenomenon does not occur because of the segregation of strains of paracrinkle virus that differ in virulence. No certain interpretation can be given, but it seems likely that symptoms reflect the degree to which the virus has invaded the tissues and multiplied in them. Thus, delay in the development of symptoms may mean incomplete systemic invasion, a phenomenon that also occurs sometimes with potato virus $\boldsymbol{Y}$, shoots from infected tubers developing at first normally and virus-free and later becoming infected (Bawden \& Kassanis, 1946).

Unless otherwise stated, inoculations were made by lightly dusting the leaves of test plants with either carborundum powder (400 mesh) or celite (a diatomaceous earth) and then rubbing them with the forefinger dipped in inoculum. The inoculum was juice obtained by macerating leaves in a pestle and mortar, and for paracrinkle virus usually came from severely diseased Arran Victory plants in their second or third year with paracrinkle, or from King Edward plants. Healthy potatoes of named varieties were all derived from the virus-free stocks selected at the Virus Research Station, Cambridge, and were kindly supplied by Dr Kenneth M. Smith. Unnamed varieties were supplied by Mr E. M. Hutton and were tuber progenies from seedlings bred in recent years. Current-year seedlings were from seed set by Majestic and Gladstone plants and supplied by Dr G. Cockerham. No known viruses were detected in any of these plants, although they were rigorously and frequently tested both by serological methods and by inoculation to such differential hosts as tobacco, tomato, Nicotiana glutinosa and Datura stramonium.

All specimens that were examined with the electron microscope were also tested by inoculation to this range of hosts, to ensure freedom from such viruses as potato $X, Y, A$, tobacco mosaic and cucumber mosaic. None of these was ever found, and we have no reason to suspect that any of our plants was infected with any known virus except paracrinkle. Clarified sap was used for preparing electron micrographs. Leaf laminae lightly sprinkled with $\mathrm{Na}_{2} \mathrm{HPO}_{4}$ were crushed with a pestle in a mortar, and the sap expressed through muslin. The sap was frozen overnight, thawed and clarified by centrifugation at 8000 r.p.m. Mounts for electron microscopy were made by placing small drops 
of the clarified sap on the usual collodion-covered specimen grids; the drops were allowed to remain on the grid for about a minute, when the liquid was sucked off with a micropipette. The mounts were washed by dipping in distilled water, dried on hard filter-paper, and then shadowed with a $0.6-0.8 \mathrm{~m} \mu$. thickness of palladium, which was cast at an angle of about 12 degrees from the plane of the mount. The electron microscope was an R.C.A. model B, fitted with a three-electrode electron gun and used with an accelerating potential of $50 \mathrm{kV}$. Much of the work was solely visual, the searching of many fields to determine whether rod-shaped particles were present, and for this the extra illumination obtainable with the modified electron gun proved extremely valuable. Electron micrographs were usually taken at an instrumental magnification of about 10,000 times, the condenser being defocused to give the minimum brightness of illumination needed for visual focusing of the selected images.

\section{RESULTS}

\section{Mechanical transmission of paracrinkle virus}

Salaman \& Le Pelley (1930) obtained no evidence that anything could be transmitted from apparently normal King Edward plants to other potato varieties or to tobacco and $D$. stramonium, by inoculation of expressed sap. So, too, with one exception, they failed to obtain transmissions from Arran Victory plants with paracrinkle. The one exception may have been a transmission of paracrinkle virus, but the results were equivocal as the inoculum also caused a mosaic in President potato plants, which carry paracrinkle, and gave a mosaic in $D$. stramonium, suggesting that there may have been a contamination with a strain of potato virus $X$. Since their work, it has been found that the transmissibility of some viruses by inoculation is greatly facilitated by incorporating certain abrasives in the inocula (Rawlins \& Tompkins, 1936; Kalmus \& Kassanis, 1945), and by preconditioning the host plants by keeping them under reduced illumination (Bawden \& Roberts, 1947, 1948). Thus it seemed worth re-examining the possibilities of transmitting paracrinkle virus by mechanical inoculation with sap.

A preliminary test in 1948 suggested that this could be done, although not readily. Sap from an Arran Victory plant with paracrinkle was inoculated to ten healthy plants, one of which developed a mild blotchy mottle. The symptoms were less severe than those in grafted plants, but when the tubers were planted in 1949 they gave rise to plants with characteristic reactions. There was some difference in the severity of symptoms in individual plants, particularly early in the season, but no more than occurs with the progeny of plants infected by grafting.

In 1949 more extensive tests were made. In March, thirty healthy Arran Victory plants were inoculated with sap from a paracrinkle plant; twenty had been kept under normal glasshouse conditions and ten had been kept in darkness for the 4 days immediately before they were inoculated. Two plants in each set developed a blotchy mottling and showed some ruffling and waving of the leaves (Pl. 1, fig. 1). Other plants, however, had become infected, but had 
shown no symptoms. This was demonstrated by harvesting the tubers in June, breaking their dormancy and planting them again, when, in addition to the progeny from the four plants that had previously shown symptoms, progeny from six others, four of which were from plants placed in the dark before inoculation, showed unmistakable symptoms of paracrinkle. Comparable results were obtained in a second experiment in April with thirty Arran Victory plants, fifteen of which were placed in the dark for 3 days before being inoculated with sap from a paracrinkle Arran Victory. Five of this fifteen developed symptoms within a fortnight of inoculation, whereas all those not placed in the dark remained apparently healthy. Again more infections had occurred than had appeared, and when tubers were replanted, those from six plants that had been kept in the dark, and from two that had not, produced plants with characteristic symptoms. Thus, of a total of sixty Arran Victory plants inoculated, at least eighteen became infected, six of the thirty-five kept under normal glasshouse conditions and twelve of the twenty-five placed in the dark for some days immediately before inoculation.

Sap from diseased Arran Victory plants was used as the inoculum for these tests, on the assumption that it might contain more virus than sap from King Edward plants. This assumption may well have been wrong, for of three Arran Victory plants that were inoculated in May with sap from a King Edward, two developed symptoms of paracrinkle. Later tests, in which tomato plants were inoculated, also suggested that King Edward plants are as good a source of virus as diseased Arran Victory. Although $100 \%$ transmission was not obtained in the inoculation tests with potatoes, the results were adequate to show that graft-transmission is not obligatory for paracrinkle virus; it seems that previous failures occurred because the virus content of sap is low, below that needed to cause infection when potatoes are simply rubbed or scratched with sap, and is about the minimum infecting dose with such additional aids as suitable abrasives and lowering the resistance of plants by keeping them in the dark. Paracrinkle virus is not unique in this respect; potato virus $A$, for example, has been transmitted by inoculation from infected to healthy potato plants only with the aid of an abrasive (Bawden, 1936). Paracrinkle and potato virus $A$ also seem to resemble one another in being more readily transmitted by inoculation to certain other hosts than to potato.

The sap from diseased Arran Victory plants, used as.inoculum in the experiments already described, was inoculated with the aid of celite to five plants each of tobacco, tomato and $D$. stramonium, partly to ensure its freedom from potato virus $\boldsymbol{X}$ or other possible contaminants and partly to see whether these species could be infected. None of them developed any symptoms, but a month later scions were taken from them and grafted on to healthy Arran Victory plants. All the plants grafted with tobacco and D. stramonium scions remained healthy, whereas the five grafted with tomato scions developed paracrinkle (Pl. 1, fig. 2). The fact that the tomato is a symptomless carrier of paracrinkle virus and is more readily infected than potato by inoculation was confirmed in other tests. In one test, four different inocula were used, namely, sap from either King Edward or diseased Arran Victory, each with and without celite. None 
of the tomato plants showed any obvious symptoms, but that infections had occurred was shown when one plant from each treatment was grafted to a healthy Arran Victory plant, for all of the grafted plants developed symptoms of paracrinkle. Only one plant from each treatment could be tested in this manner as we had only four remaining Arran Victory plants, but examination with the electron microscope of clarified sap from the inoculated tomatoes suggested that all of them had become infected. Thus, the virus can be transmitted to tomato from potato without the aid of an abrasive, in the same manner as potato virus $A$ can be transmitted to tobacco (Bawden, 1936). Other results from electron microscopy also suggest that the virus is readily transmissible from infected to uninfected tomato plants by inoculation of sap without using any abrasive; with the aid of celite, we have produced infection using tomato sap diluted 1 in 1000.

\section{Rod-shaped particles in infected and uninfected potatoes}

When examined with the electron microscope, clarified sap from King Edward plants and from Arran Victory with paracrinkle was found to contain rod-like particles of varying lengths but a constant width of about $10 \mathrm{~m} \mu$. (Pl. 1, fig. 3). In other solanaceous species examined, for example, tobacco, tomato, D. stramonium and Nicotiana glutinosa, similar particles were found in plants infected separately with a number of different viruses, but not in uninfected seedlings. Their relevance to paracrinkle virus, however, was rendered uncertain by the fact that apparently similar, though fewer, particles occurred in clarified sap from uninfected Arran Victory plants (Pl. 1, fig. 4). Examination of sap from the five plants each of tomato, tobacco and Datura stramonium, already mentioned as having been inoculated with paracrinkle virus and grafted back to healthy Arran Victory, showed that some rod-like particles could be transferred from potato to tomato plants. All five tomato plants contained rod-like particles indistinguishable from those in the potato (Pl. 1, fig. 5), whereas no such particles were found in any of the tobacco or D. stramonium plants. As only the tomato plants produced paracrinkle when grafted to Arran Victory, this suggested a connexion between the rods and the virus, though it was inconclusive, for the rod-shaped particles present in uninfected potatoes might also be transmissible to tomato, but not to tobacco and $D$. stramonium.

Further studies were therefore made to determine the occurrence and properties of such particles in normal potato plants. In addition to Arran Victory, sap from the varieties Arran Banner, Arran Pilot, British Queen, Craig's Defiance, Great Scot, Katahdin and Kerr's Pink, and from two of Hutton's new varieties, numbers 11-76 and 11-84, was examined with the electron microscope, and similar rod-shaped particles were found in all. Their occurrence in the last two suggested that the rods are normal constituents of potato leaves, and not viruses which the varieties might have contracted from external sources and be carrying symptomlessly. Support for this interpretation was provided by raising seedlings, from seed set by Majestic and Gladstone, in insect-proofed glasshouses, conditions that preclude natural infections with 
most viruses. Sap was taken from six such seedlings when they were about $4 \mathrm{in}$. high, and similar rod-shaped particles were found in all. Preliminary tests suggest that more of these rods occur in extracts of macerated petioles than of leaf laminae.

Tests were next made to determine whether these particles from uninfected potato plants could be transmitted to other species. Sap from all the varieties and the current-year seedlings was inoculated to tobacco, tomato and Nicotiana glutinosa plants, and scions from each variety were also grafted on to tomato plants. A month later, sap from the inoculated and grafted plants was examined with the electron microscope, and with one exception no rods were found in any. The exception was one mount from the tomato plant grafted with 11-84, in which two rods only were seen. Further preparations were made from this plant, but no more rods were seen. No positive interpretation of this one result can be given; it is unlikely that the plant had become accidentally infected with a rod-shaped virus, for had this happened later examinations should have shown more rods, and the test plants inoculated with the preparation all remained healthy. The rods may have been bacterial flagella or some other material accidentally introduced during the preparation of the mount. These negative results from control potatoes contrast sharply with those obtained when similar transmissions were made from King Edward or from Arran Victory plants infected with paracrinkle virus, for then rod-shaped particles were readily and regularly found in every tomato plant. This suggests strongly that the rods found in the inoculated tomato plants are paracrinkle virus, though this cannot be demonstrated conclusively. In this connexion, it is significant, too, that more rods occur in sap from leaf laminae of King Edward and from diseased Arran Victory plants than in sap from other varieties or from healthy Arran Victory, although accurate quantitative studies are impossible. The fact that fewer rods were found in sap from Arran Victory leaves that showed slight symptoms of paracrinkle than from those that were severely diseased, also suggests a connexion with the virus, and that variations in symptoms reflect differences in the extent to which the virus has multiplied and become fully systemic. Further support for this interpretation is the fact that inoculations with sap from severely diseased Arran Victory leaves to tomato plants have always transmitted rod-shaped particles, whereas they have sometimes failed with sap from those showing only slight symptoms.

These results give no information about the chemical nature of the rods either in healthy plants or in those infected with paracrinkle virus. The two differ considerably in their resistance to heating; the presumed rods of paracrinkle virus in sap from infected tomato plants began to disappear after heating for $10 \mathrm{~min}$. at $55^{\circ} \mathrm{C}$. and none was found after $10 \mathrm{~min}$. at $60^{\circ}$. By contrast, those in healthy Arran Victory, Katahdin and 11-84, all withstood heating to over $90^{\circ}$ (Pl. 1, fig. 6). When King Edward sap was heated at $90^{\circ}$, the number of rods was much reduced, suggesting that the paracrinkle virus had been destroyed, and that this variety also contains heat-resistant rods similar to those occurring in other potato varieties. The presumed paracrinkle particles in sap from infected tomato leaves were precipitated by one-third 
saturation with ammonium sulphate and redissolved in water apparently unchanged. Few of the rods in sap from uninfected potato plants were precipitated at this salt concentration, but more concentrated preparations will be needed before critical tests on their precipitability can be made.

\section{DISCUSSION}

Although our results suggest that paracrinkle virus may be morphologically similar to particles that occur in uninfected potato plants, the two differ so widely in their other properties that there is no reason to assume they are in any way connected. The preliminary studies of the properties of the presumed paracrinkle virus suggest that it resembles such other relatively unstable plant viruses as potato $\boldsymbol{Y}$, which also has rod-shaped particles of about the same width (Bawden \& Nixon, unpublished). It is a reasonable assumption that paracrinkle virus may also resemble this in being a protein, but there is no evidence on which to base even a guess at the chemical nature of the rod-shaped particles present in sap from apparently virus-free potatoes. These may also be proteins, but their stability on heating is greater than that of even tobacco mosaic virus, the most heat-resistant of the known rod-shaped viruses, and they could equally well be cellulose. Therefore we have no evidence to suggest that paracrinkle virus is a modification of any constituent of normal potatoes.

Our results do not disprove the contention that paracrinkle virus arose de novo in the variety King Edward, though they do seem to make it an unnecessary postulate. The conclusion that the virus is transmitted only by grafting was clearly premature, as also may be the assumption that it occurs naturally only in King Edward. It is readily transmissible to tomato, but this host shows no symptoms and hence infected plants would normally pass unrecognized, and it is extremely unlikely that tomato is the only host that behaves in this manner. The assumption that the virus does not spread in the field and therefore could not have spread to King Edward was based on the fact that there is no record of intolerant potato varieties, such as Arran Victory, being naturally infected. This fact does not prove that infections never occur, but only that they are too few to attract attention. Our results show that Arran Victory, although highly sensitive when infected, is also highly resistant to infection, and the absence of natural infections in it is no evidence that spread may not occur more often to other hosts. There are other viruses that spread rapidly in one host but not in another; for example, dandelion yellow mosaic virus will pass from an infected dandelion to lettuce and then spread rapidly from lettuce to lettuce, but it very rarely spreads from one dandelion plant to another (Kassanis, 1947). Different potato varieties differ widely in the readiness with which they become infected with viruses such as potato $Y$ and leaf roll (Bawden \& Kassanis, 1946), and this may also be true with paracrinkle virus. As we have no stock of King Edward free from paracrinkle virus, its susceptibility to infection cannot be tested, but it may be higher than that of Arran Victory. If this is so, there is no need to assume that the original seedling contained the virus, for spread from an initial infection occurring later 
in the life of the variety could soon have led to the whole clone becoming infected. Also, until King Edward is obtained free from paracrinkle, even to call it a symptomless carrier remains somewhat of an assumption. The variety crops less well than most others that are widely grown, which is one reason for the higher price charged for King Edward tubers, and the leaves are smaller than those of most other varieties and they are also characteristically ruffled and waved. In attempts to obtain virus-free lines for experimental purposes, we have kept King Edward tubers for periods up to 25 days at temperatures around $38^{\circ}$, a treatment effective in curing plants from leaf roll (Kassanis, 1949), but all the tubers that survived the treatment were still infected. As our results from heating in vitro indicate a thermal inactivation point of about $55^{\circ}$, this suggests that the virus has a large thermal coefficient of inactivation, a further feature that relates it with other viruses that have rod-shaped particles.

It has long been recognized that effects similar to those caused by viruses are also caused by genes, plasmagenes and hormones, and the relationships between these factors provide a fertile field for speculation. There is nothing intrinsically improbable in the idea that viruses may originate from normal cell components, or that components which are normal in one species may act as viruses when transferred to another, but it cannot be entertained seriously until some evidence is forthcoming that uninfected plants contain particles resembling known viruses. Our results have provided none and have shed no light on the possible origin of paracrinkle virus; they have, however, brought this virus more into line with others that have been studied and thereby abolished the seemingly unique features that have previously been attributed to it. There would seem now to be no need to assume any different relationship between King Edward and paracrinkle virus than that between any other vegetatively propagated host and a virus that it tolerates.

\section{REFERENCES}

Barton-Wright, E. C. \& McBain, A. (1933). Studies in the physiology of the virus diseases of the potato. II. A comparison of the carbohydrate metabolism of normal with that of crinkle potatoes; together with some observations on carbohydrate metabolism in a 'carrier' variety. Ann. appl. Biol. $20,525$.

BAwDEN, F. C. (1936). The viruses causing a top necrosis (acronecrosis) of the potato. Ann. appl. Biol. 23, 487.

Bawden, F. C. (1939). Plant Viruses and Virus Diseases, 1st ed. Leiden: Chronica Botanica.

Bawden, F. C. \& Kassanis, B. (1946). Varietal differences in susceptibility to potato virus $Y$. Ann. appl. Biol. 33, 46.

Bawden, F. C. \& Roberts, F. M. (1947). The influence of light intensity on the susceptibility of plants to certain viruses. Ann. appl. Biol. 34, 286.

Bawden, F. C. \& Roberts, F. M. (1948). Photosynthesis and predisposition of plants to infection with certain viruses. Ann. appl. Biol. 35, 418.

Carson, G. P., Howard, H. W., Markham, R. \& Smith, K. M. (1944). Paracrinkle virus and inheritance. Nature, Lond., 154, 334.

Darlington, C. D. (1944). Heredity, development and infection. Nature, Lond., $154,164$.

Darlington, C. D. (1949). Les plasmogenes. Coll. Inter. Centre Nat. Rech. Sci. 8, 123. 
Kalmus, H. \& Kassanis, B. (1945). The use of abrasives in the transmission of plant viruses. Ann. appl. Biol. 32, 230.

Kassanis, B. (1947). Studies on dandelion yellow mosaic and other virus diseases of lettuce. Ann. appl. Biol. 34, 412.

Kassanis, B. (1949). Potato tubers freed from leaf-roll virus by heat. Nature, Lond., $163,88$.

Plank, J. E. van der (1948). Origin of some plant viruses. Nature, Lond., 162, 291.

Rawuins, T. E. \& Tomprins, C. M. (1936). Studies on the effect of carborundum as an abrasive in plant-virus inoculation. Phytopath. 26, 578.

Salaman, R. N. (1932). The analysis and synthesis of some diseases of the mosaic type. The problem of carriers and auto-infection in the potato. Proc. Roy. Soc. B, $110,186$.

Salaman, R. N. \& Le Pelley, R. H. (1930). Para-crinkle: a potato disease of the virus group. Proc. Roy. Soc. B, 106, 140.

\section{EXPLANATION OF PLATE}

Fig. 1. Leaves from Arran Victory potato plant infected with paracrinkle by inoculation with sap from a diseased Arran Victory.

Fig. 2. Arran Victory potato plant developing paracrinkle after being grafted with a scion from a symptomless tomato plant previously inoculated with sap from a King Edward potato plant.

Fig. 3. Electron micrograph of sap from leaf laminae of an Arran Victory plant with paracrinkle showing rod-shaped particles of variable lengths. $\times \mathbf{2 6 , 5 0 0}$.

Fig. 4. Electron micrograph of sap from leaf laminae of uninfected Arran Victory plant. The rod-shaped particles are similar to, but fewer than, those in comparable preparations from paracrinkle plants. $\times 26,500$.

Fig. 5. Electron micrograph of sap from leaf laminae of tomato plant inoculated with sap from a King Edward potato plant. No such rod-shaped particles occur in uninfected tomato and they are presumed to be particles of paracrinkle virus. $\times \mathbf{2 6 , 5 0 0}$.

Fig. 6. Electron micrograph showing rod-shaped particles from uninfected potato plant after heating sap for $10 \mathrm{~min}$. at $98^{\circ} \mathrm{C} . \times 26,500$.

(Received 23 August 1949) 
Journal of General Microbiology, Vol. 4, No. 2
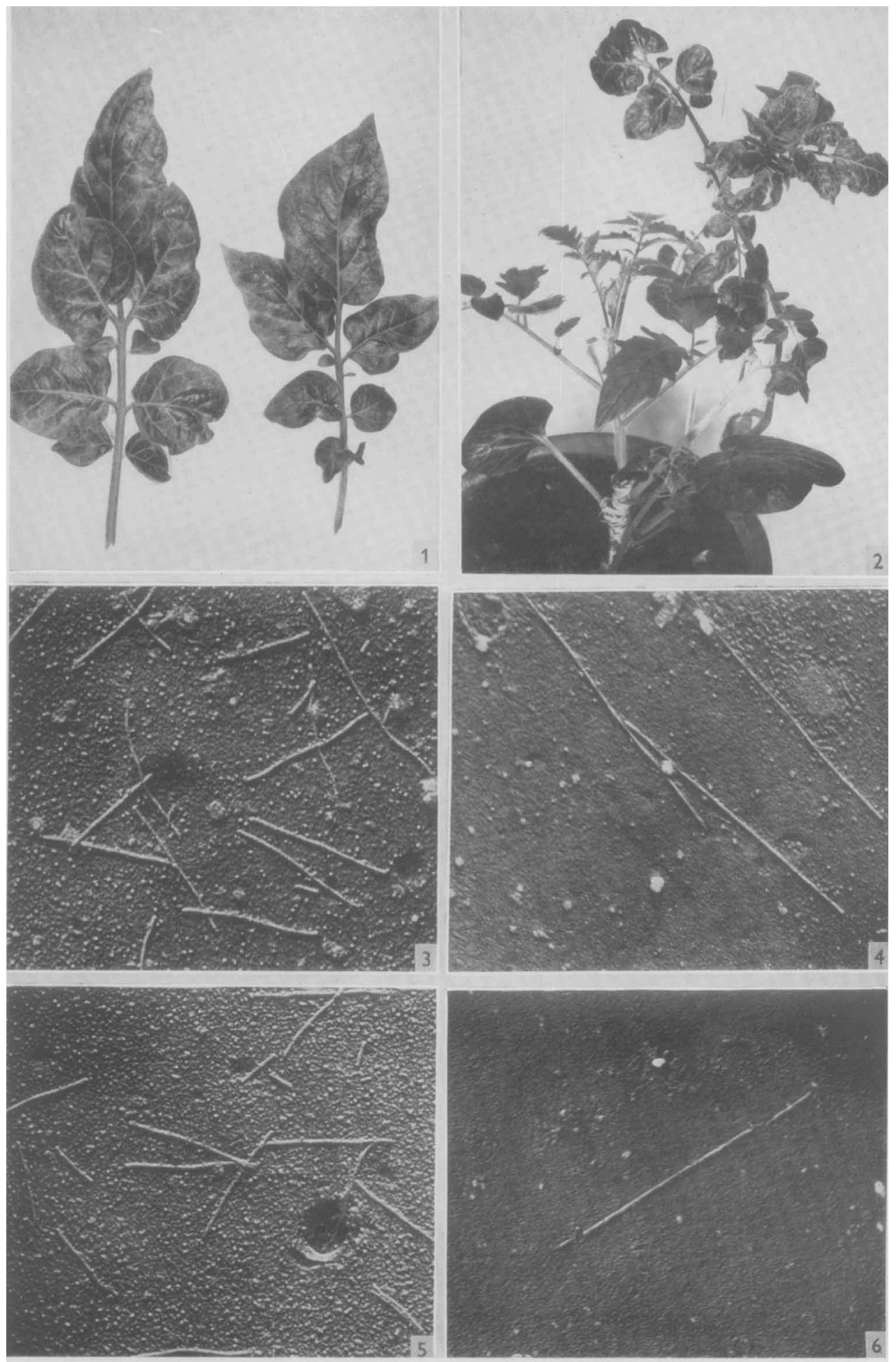

Figs. 1-6

F. C. Bawden, B. Kassanis \& H. L. Nixon-Potato paracrinkle virus. Plate 1 